\title{
STUDIES ON THE BIOSYNTHESIS OF TERRECYCLIC ACID A, AN ANTITUMOR ANTIBIOTIC FROM ASPERGILLUS TERREUS
}

\author{
John M. Beale, Jr., Robert L. Chapman and John P. N. Rosazza* \\ Division of Medicinal Chemistry and Natural Products, \\ College of Pharmacy, University of Iowa, \\ Iowa City, Iowa 52242, USA \\ (Received for publication May 15, 1984)
}

\begin{abstract}
The biosynthesis of terrecyclic acid $\mathrm{A}$ was investigated using ${ }^{13} \mathrm{C}$-labeled acetates and mevalonate. ${ }^{13} \mathrm{C}$ NMR spectral analysis of isolated labeled terrecyclic acid demonstrated that the structure is assembled via an isoprene pathway.
\end{abstract}

Aspergillus terreus Thom is a prolific producer of secondary products ${ }^{1}$ including the antitumor sesquiterpenes terrecyclic acid $(\mathbf{1})^{2,3)}$ and the structurally related lactone derivative quadrone $(2)^{4}$ (Fig. 1). These compounds are structurally unique among the antitumor sesquiterpenes, and studies on the biosynthesis of quadronoids were undertaken with the goal of establishing their mode of assembly by $A$. terreus. This information would be of mechanistic interest, and could be used to suggest useful and structurally-related compounds which might also be produced by this fungus.

Quadronoids like terrecyclic acid A appear to be terpenoid in origin, but an analysis of their structures indicates that they could also arise by mixed terpenoid/polyketide biosynthetic pathways. HiRota et al..$^{5)}$, and CANE et $a l .{ }^{8)}$, recently obtained evidence by feeding ${ }^{13} \mathrm{C}$-labeled acetates which support a completely terpenoid origin for quadrone and terrecyclic acid A. Mechanisms whereby these compounds could be assembled beginning with a fifteen-carbon farnesyl pyrophosphate precursor have been proposed. This paper describes the labeling pattern of terrecyclic acid $\mathrm{A}$ enriched with $\left[1-{ }^{13} \mathrm{C}\right]$, $\left[2-{ }^{13} \mathrm{C}\right]$, and $\left[1,2-{ }^{13} \mathrm{C}_{2}\right]$ acetates, and $\left[2-{ }^{13} \mathrm{C}\right]$ and $\left[5-{ }^{13} \mathrm{C}\right]$ mevalonic acids as determined by ${ }^{13} \mathrm{C}$ NMR.

\section{Materials and Methods}

Microorganism

A. terreus, Thom, NRRL 11,156 ${ }^{1)}$ was used as the terrecyclic acid A producing organism.

General

NMR spectra were obtained at a field strength of $90.56 \mathrm{MHz}$ on a Bruker WM-360 FTQ NMR spectrometer equipped with an Aspect 2000 data system and an Aspect 2000 pulse programmer. Spectra were acquired in the FT mode, and quadrature detection was employed. A spectral width of $23809.5 \mathrm{~Hz}$ was used, and the transform contained $32 \mathrm{~K}$ data points. In all cases the pulse width was calibrated to 
give a carbon nuclear flip angle of 30 degrees, and the acquisition time was 0.688 second. The broadband decoupler was operated at an offset equal to the deuterium resonance frequency of the solvent $\mathrm{CDCl}_{3}$, and the decoupler power was $9 \mathrm{H}$ at an attenuation of $3 \mathrm{~dB}$. The Bruker $5 \mathrm{~mm}$ carbon/proton probe was employed for all of the spectra obtained in this work, and $5 \mathrm{~mm}$ tubes were used with the sample dissolved in $0.4 \mathrm{ml} \mathrm{CDCl}_{3}$.

Liquid scintillation counting was accomplished with a Beckman LSC-2 liquid scintillation counter with Hydrofluor (National Diagnostics Co.) as the fluor.

Chromatography

Thin-layer chromatography (TLC) was performed by extracting 2-ml volumes of culture broths with $0.5 \mathrm{ml}$ of $\mathrm{CHCl}_{3}$. Aliquots of $50 \mu \mathrm{l}$ of $\mathrm{CHCl}_{3}$ were spotted onto $0.25 \mathrm{~mm}$ silica gel GF-254 (Merck) TLC plates which were developed in $\mathrm{CHCl}_{3}-\mathrm{Me}_{2} \mathrm{CO}$ - benzene - formic acid $(95: 5: 5: 1)$. Developed TLC plates were visualized under $254 \mathrm{~nm}$ UV light, and were sprayed with a $0.5 \%$ 2,4-dinitrophenylhydrazine in $2 \mathrm{~N} \mathrm{HCl}$ reagent. Terrecyclic acid A appeared as a yellow spot at $\mathrm{Rf} 0.29$ under these conditions.

High performance liquid chromatography (HPLC) was performed with a Waters Associates ALC/ GPC 202 instrument equipped with an M6000 solvent delivery system, U6K Universal Injector, and a $254 \mathrm{~nm}$ fixed wavelength differential UV detector. Samples of clear culture supernatants obtained by bench top centrifugation at $2,000 \times g$ for 10 minutes were directly injected into the system which was linked to a PRP-1 (Hamilton, $0.41 \times 15 \mathrm{~cm}, 10 \mu \mathrm{m}$ polystyrene-divinylbenzene) column. Samples were eluted with an $\mathrm{CH}_{3} \mathrm{CN}-\mathrm{H}_{2} \mathrm{O}$ - formic acid (40:60:1) solvent system at a flow rate of $1.5 \mathrm{ml} /$ minute at a nominal operating pressure of $77.3 \mathrm{~kg} / \mathrm{cm}^{2}$. Under these conditions, 2 possessed a retention volume of $8.3 \mathrm{ml}$. Titers of terrecyclic acid A were measured by comparison to a standard peak-height concentration curve which was linear over the range of $0.2 \sim 25 \mu \mathrm{g}$ of the compound. Semi-preparative separations of terrecyclic acid A from isotopically enriched incubations were accomplished using a larger PRP1 column (Hamilton, $0.7 \times 30.5 \mathrm{~cm}$ ) and an eluant of $\mathrm{CH}_{3} \mathrm{CN}-\mathrm{H}_{2} \mathrm{O}$ (4: 6). Under these conditions, terrecyclic acid A possessed a retention volume of $63 \mathrm{ml}$.

\section{Fermentation}

A. terreus was maintained on slants of potato-dextrose agar (Difco) in sealed, screw-cap tubes which were stored in a refrigerator at $4{ }^{\circ} \mathrm{C}$ until used. Incubations were conducted in 1-liter steel-capped DeLong flasks, each containing $100 \mathrm{ml}$ of the following medium (amounts per liter): glucose $40 \mathrm{~g}$, Bactopeptone (Difco) $5 \mathrm{~g}, \mathrm{~K}_{2} \mathrm{HPO}_{4} 0.25 \mathrm{~g},\left(\mathrm{NH}_{4}\right)_{6} \mathrm{Mo}_{7} \mathrm{O}_{24} \cdot 4 \mathrm{H}_{2} \mathrm{O} 5 \mathrm{mg}, \mathrm{FeSO}_{4} \cdot 7 \mathrm{H}_{2} \mathrm{O} 50 \mathrm{mg}, \mathrm{CuSO}_{4} \cdot 5 \mathrm{H}_{2} \mathrm{O}$ $5 \mathrm{mg}, \mathrm{MnSO}_{4} \cdot 7 \mathrm{H}_{2} \mathrm{O} 10 \mathrm{mg}, \mathrm{pH} 7.1$ without adjustment. Complete media were autoclaved at $121^{\circ} \mathrm{C}$, $0.7 \mathrm{~kg} / \mathrm{cm}^{2}$ pressure for 20 minutes. Fermentations were incubated with shaking at $250 \mathrm{rpm}$ at $28^{\circ} \mathrm{C}$ in New Brunswick Scientific G-25 gyrotory shakers. First stage cultures were initiated with one slant each per $100 \mathrm{ml}$ of culture medium, and 48 hour-old first stage cultures were used to provide $10 \%$ inocula for the terrecyclic acid A production culture ${ }^{7)}$.

For analysis, 2-ml samples were withdrawn from production culture flasks at 24-hour intervals. The $\mathrm{pH}$ and percent glucose (Testape, Lilly) were measured, and the sample was centrifuged for 10 minutes at $2,000 \times g$ to provide a clear supernatant solution suitable for extraction for TLC, or direct injection for HPLC analysis.

\section{Addition of Labeled Precursors to Production Cultures}

Biosynthetic investigations were conducted with both ${ }^{14} \mathrm{C}$ - and ${ }^{13} \mathrm{C}$-labeled precursors. Radioactive precursors were obtained from New England Nuclear, Boston, MA. Stable, isotopically-labeled precursors were purchased from Merck Sharp and Dohme Isotopes, St. Louis, MO. The purity of ${ }^{13} \mathrm{C}-$ precursors was established by ${ }^{13} \mathrm{C}$ NMR spectral analysis. Labeled compounds were added in one dose to 5-day old production stage cultures when HPLC analysis indicated that terrecyclic acid A production had just begun. This normally coincided with the detection (by HPLC) of $5 \sim 10 \mathrm{mg} / \mathrm{liter}$ of the antibiotic. Radioisotopes were added in $5 \mu \mathrm{Ci}$ amounts $/ 100 \mathrm{ml}$ of culture along with $0.1 \mathrm{~g}$ of non-labeled carrier. The following radioactive precursors were used: $\left[1-{ }^{14} \mathrm{C}\right]$ acetate; $(R, S)-\left[2-{ }^{14} \mathrm{C}\right]$ mevalonolactone; and $\left[\right.$ methyl $\left.-{ }^{14} \mathrm{C}\right]$ methionine. Concentrations of stable isotopic precursors were $0.1 \mathrm{~g} / 100 \mathrm{ml}$ of culture. Identical amounts of non-labeled precursors were added to other cultures which were carried along as 
controls.

Volumes of production-stage cultures, amounts of each ${ }^{13} \mathrm{C}$-labeled precursor fed, and the amount of labeled terrecyclic acid A obtained were as follows: $500 \mathrm{mg}$ of 90 atom \% sodium $\left[1-{ }^{13} \mathrm{C}\right]$ acetate in $500 \mathrm{ml}$ of culture, $20 \mathrm{mg}$ of terrecyclic acid A; $500 \mathrm{mg}$ of 91.9 atom \% sodium $\left[2-{ }^{13} \mathrm{C}\right]$ acetate in $500 \mathrm{ml}$ of culture, $27 \mathrm{mg}$ of terrecyclic acid A; $500 \mathrm{mg}$ of 99 atom \% sodium $\left[1,2-{ }^{13} \mathrm{C}_{2}\right]$ acetate in $500 \mathrm{ml}$ of culture, $25 \mathrm{mg}$ of terrecyclic acid A; $300 \mathrm{mg}$ of 90 atom \% DL-[2- $\left.{ }^{13} \mathrm{C}\right]$ mevalonic acid lactone in $300 \mathrm{ml}$ of culture, $30 \mathrm{mg}$ of terrecyclic acid A; $100 \mathrm{mg}$ of 90 atom $\%$ DL-[5- $\left.{ }^{13} \mathrm{C}\right]$ mevalonic acid lactone in $100 \mathrm{ml}$ of culture, $7 \mathrm{mg}$ of terrecyclic acid A.

\section{Extraction and Purification of Labeled Terrecyclic Acid}

Fermentations were incubated for five additional days after the addition of labeled precursors at which time HPLC indicated that terrecyclic acid A titers had reached peak levels. Each fermentation was terminated by extraction with four volumes of $\mathrm{CHCl}_{3}$. Extracts were dried over anhydrous sodium sulfate and evaporated to dryness under vacuum. Labeled terrecyclic acid A samples were purified by preparative HPLC as described. Removal of the solvent from terrecyclic acid A-containing fractions afforded chromatographically pure compound which was subjected to mass spectral, ${ }^{1} \mathrm{H}$ NMR and ${ }^{13} \mathrm{C}$ NMR spectral analyses. Typical isolated yields of labeled terrecyclic acid A from these experiments were $60 \mathrm{mg} /$ liter.

\section{Results}

Terrecyclic acid A was isolated from multiliter scale fermentations with our strain of $A$. terreus NRRL 11,156 and completely characterized by melting point, UV, ${ }^{1} \mathrm{H}$ NMR, ${ }^{13} \mathrm{C}$ NMR and high resolution mass spectrometric analyses, all of which were identical to values reported earlier by NAKAGAWA and coworkers $^{3)}$. In addition, our isolated sample of terrecyclic acid A could be thermally converted ${ }^{8)}$ into quadrone which was fully comparable to an authentic sample of 2 obtained from CALTON ${ }^{2)}$. No quadrone was produced by $A$. terreus under the incubation and extraction conditions used in this work.

${ }^{13} \mathrm{C}$ NMR spectral assignments were made on the basis of delayed decoupled multiplicity analyses, simple chemical shift rules, and by spectral comparisons of quadrone and terrecyclic acid, and a variety of chemically-altered quadronoids. Proton chemical shifts of methyl groups were distinguished by lanthanide shift reagent NMR experiments (unpublished data). Spectral assignments determined by these means were essentially the same as those made by CANE et al. ${ }^{e)}$.

The optimum time for addition of biosynthetic precursors was established as day 5 in the terrecyclic acid A production culture. At this time, terrecyclic acid A biosynthetic activity was indicated by the HPLC appearance of approximately 5 to $10 \mathrm{mg} /$ liter of terrecyclic acid in the culture medium. Addition of precursors at the exact start of terrecyclic acid A production resulted in high incorporations, and an actual enhancement of peak titers of terrecyclic acid A. The optimum time for harvest of cultures as determined by HPLC analyses was 5 days following addition of labeled precursors.

Terrecyclic acid A was labeled with both radioactive acetate and mevalonic acid, but methionine was not incorporated into the compound by A. terreus. Specific activities of isolated terrecyclic acid A from $\left[1-{ }^{14} \mathrm{C}\right]$ acetate and $\left[2-{ }^{14} \mathrm{C}\right]$ mevalonate were $1.06 \mu \mathrm{Ci} / \mu \mathrm{mol}$ and $2.55 \mu \mathrm{Ci} / \mu \mathrm{mol}$, respectively, indicating specific incorporations of radioactive precursors of 2.0 and $6.0 \%$. By this measure, mevalonic acid was incorporated three times as efficiently as acetate by the microorganism.

When ${ }^{13} \mathrm{C}$-labeled acetates and mevalonates were added to A. terreus cultures, terrecyclic acid A was isolated by solvent extraction, and purified by preparative HPLC to provide between $7 \sim 30 \mathrm{mg}$ of labeled products in each experiment. These terrecyclic acid A samples were subjected to ${ }^{13} \mathrm{C}$ NMR spectral analyses, and peak intensity difference measurements between labeled and natural abundance 
Table 1. Relative enrichment data from ${ }^{13} \mathrm{C}$-labeled precursor experiments.

\begin{tabular}{|c|c|c|c|c|c|c|}
\hline \multirow[b]{2}{*}{ Carbon } & \multirow{2}{*}{$\begin{array}{l}\text { Chemical } \\
\text { shift (ppm) }\end{array}$} & \multicolumn{4}{|c|}{ Relative enrichments ${ }^{1}$ from } & \multirow{2}{*}{$\begin{array}{c}{\left[1,2-{ }^{13} \mathrm{C}_{2}\right]-} \\
\text { Acetate }^{2}\end{array}$} \\
\hline & & $\begin{array}{l}R S-\left[5-{ }^{13} \mathrm{C}\right]- \\
\text { Mevalonate }\end{array}$ & $\begin{array}{l}R S-\left[2-{ }^{13} \mathrm{C}\right]- \\
\text { Mevalonate }\end{array}$ & {$\left[1-{ }^{13} \mathrm{C}\right]$ Acetate } & {$\left[2-{ }^{13} \mathrm{C}\right]$ Acetate } & \\
\hline 1 & $180.20, \mathrm{~s}$ & 0.8 & 0.7 & 1.1 & 4.2 & 55.9 \\
\hline 3 & $115.90, \mathrm{t}$ & 1.6 & $1.0 *$ & $1.0 *$ & 3.3 & 72.4 \\
\hline $3 a$ & $150.45, \mathrm{~s}$ & 1.6 & 0.4 & 2.0 & $1.0 *$ & 72.5 \\
\hline 4 & $207.20, \mathrm{~s}$ & 1.0 & 12.4 & 1.8 & 4.1 & - \\
\hline 5 & $41.46, \mathrm{t}$ & 7.6 & 1.0 & 2.5 & 1.4 & 34.8 \\
\hline $5 a$ & $46.30, \mathrm{~d}$ & 0.7 & 1.1 & 1.0 & 2.5 & 34.0 \\
\hline 6 & $48.80, \mathrm{~d}$ & 1.5 & 1.0 & 1.2 & 3.0 & 34.5 \\
\hline 7 & $28.89, \mathrm{t}$ & 8.2 & 1.1 & 3.6 & 1.4 & 33.7 \\
\hline 8 & $22.50, \mathrm{t}$ & 1.0 & 4.8 & 1.1 & 4.0 & - \\
\hline $8 \mathrm{a}$ & $47.90, \mathrm{~d}$ & 0.5 & 1.1 & 3.5 & 1.0 & 55.3 \\
\hline $8 b$ & $54.90, \mathrm{~s}$ & 2.1 & 0.8 & 0.7 & 1.7 & 31.0 \\
\hline 9 & $54.00, \mathrm{t}$ & 5.8 & 1.0 & 3.0 & 1.6 & 30.8 \\
\hline 10 & $40.40, \mathrm{~s}$ & 1.9 & 1.1 & 4.1 & 1.4 & 36.2 \\
\hline $11^{3}$ & $27.33, \mathrm{q}$ & 0.8 & 1.7 & 1.1 & 3.6 & 36.4 \\
\hline $12^{3}$ & $34.76, \mathrm{q}$ & $1.0^{*}$ & 4.9 & 1.4 & 5.4 & \\
\hline
\end{tabular}

* Peak selected as reference.

1 Relative enrichments were calculated by dividing the intensity of each line in the spectrum of the labeled compound by the intensity of the corresponding line in the natural abundance spectrum, and normalizing to give a value of 1.0 for an unenriched carbon signal ${ }^{9)}$.

$2 J \mathrm{cc}$ values in $\mathrm{Hz}$.

3 Chemical shift assignments for carbons 11 and 12 may be interchanged.

${ }^{13} \mathrm{C}$ NMR spectra of terrecyclic acid $\mathrm{A}$ were measured $^{\theta)}$. The results are shown in Table 1. Relative enrichments of terrecyclic acid from various precursors ranged from a high of 12.4 for mevalonolactone to approximately 2.0 with labeled acetates. Carbon atoms 3a, 5, 7, 8a, 9 and 10 are derived from the carboxyl carbon atom of acetate while enrichments from sodium $\left[2-{ }^{13} \mathrm{C}\right]$ acetate indicated that the remaining carbom atoms $1,3,4,5 a, 6,8,8 b, 11$ and 12 were derived from the methyl group of acetate. Re-
Fig. 2. Labeling patterns obtained when ${ }^{13} \mathrm{C}$ enriched precursors are incorporated into the structure of terrecyclic acid.
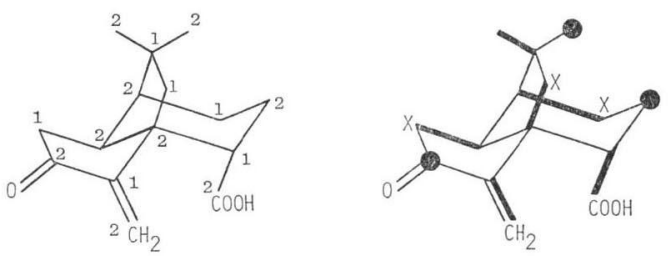<smiles>CC(=O)[O-]</smiles><smiles>[X]C1(C)COC(=O)OC1</smiles>

sults from the $\left[1,2-{ }^{13} \mathrm{C}_{2}\right]$ acetate feeding experiments are also indicated in Table 1. The level of incorporation of doubly labeled acetate was similar to that obtained with the singly labeled compounds. The ${ }^{13} \mathrm{C}$ NMR spectra of terrecyclic acid A labeled from $\left[1,2-{ }^{13} \mathrm{C}_{2}\right]$ acetate revealed six pairs of enhanced and spin-coupled carbon signals as well as three enriched but noncoupled carbon atoms. Analysis of the coupling constants indicated that the following carbon atoms were spin-coupled: 1 and $8 \mathrm{a} ; 3$ and $3 \mathrm{a}$; 5 and $5 \mathrm{a} ; 6$ and 7; and 10 and 11 . The three enriched and noncoupled carbons were at positions 4,8 and 12. An exceptionally high incorporation of ${ }^{13} \mathrm{C}$ was obtained at position 4 (a factor of 12.4) vs positions 8 and 12 (a factor of 4.8 and 4.9 respectively) with $\left[2-{ }^{13} \mathrm{C}\right]$ mevalonolactone. Positions 5,7 and 9 were highly enriched with $\left[5-{ }^{13} \mathrm{C}\right]$ mevalonolactone, but enrichments at these three carbons were more uniform.

The labeling patterns obtained with each of the ${ }^{13} \mathrm{C}$ precursors are summarized in Fig. 2. 
Fig. 3. The labeling pattern obtained when acetate is incorporated into terrecyclic acid A via isoprenoid intermediates.

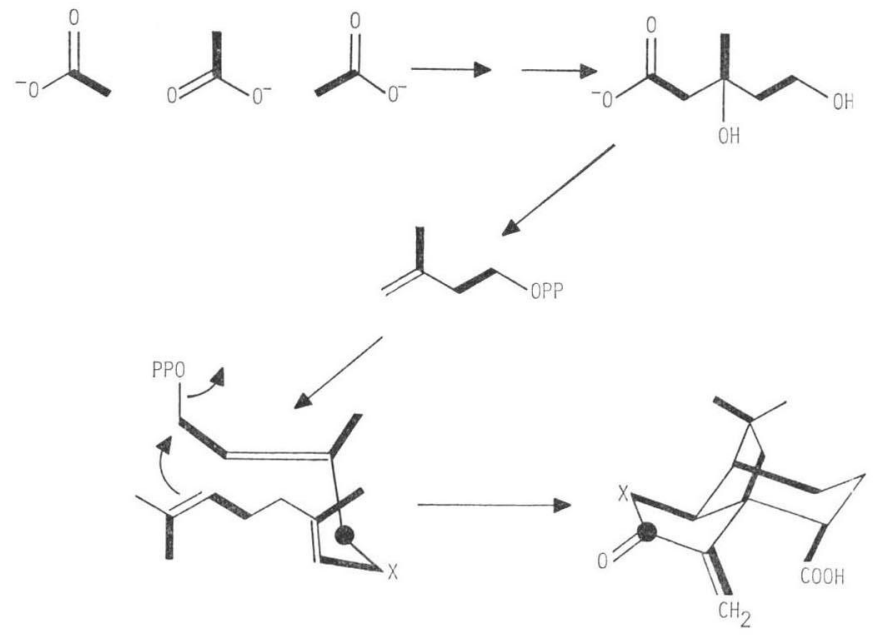

\section{Discussion}

Extensive experimentation resulted in the formulation of a culture medium and a fermentation protocol which consistently supported the production of $350 \mathrm{mg} / \mathrm{liter}$ or more of terrecyclic acid A by $A$. terreus NRRL 11,156 (unpublished data). The predictable nature of the terrecyclic acid A fermentation, and the use of direct HPLC analysis of culture broth samples without solvent extraction enabled the precise timing of addition of labeled precursors when antibiotic biosynthetic activity had commenced. All precursors were added in a single dose to obtain relatively large amounts of labeled terrecyclic acid A for spectral analysis.

The patterns obtained by incorporation of methyl and carboxyl- ${ }^{13} \mathrm{C}$-labeled acetate into terrecyclic acid A (Fig. 2) were completely complementary to one another and were identical to those reported by Hirota et al., for terrecyclic acid ${ }^{5)}$ and by CANE et al., for quadrone and terrecyclic acid ${ }^{6)}$. Results obtained by feeding $1,2-{ }^{13} \mathrm{C}_{2}$-doubly labeled acetate and mevalonic acids rule out the involvement of polyketides in the biosynthesis of terrecyclic acid (Fig. 3). The condensation of three, doubly labeled acetate units would give mevalonic acid which decarboxylates to form the 5-carbon isopentenyl pyrophosphate unit containing two sets of spin-coupled carbons and an unsplit singlet. Incorporation of three isopentenyl units into the structure of terrecyclic acid requires the spectral observations of six sets of spin-coupled doublets and three unsplit but enriched singlet signals. This is precisely the pattern observed in these experiments and by others ${ }^{5,6)}$.

Terrecyclic acid A obtained from $\left[2-{ }^{13} \mathrm{C}\right]$ mevalonic acid was labeled in positions 4,8 and 12 , the same positions containing unsplit singlets from the doubly labeled acetate experiment. The amount of mevalonic acid incorporated into position 4 was significantly higher than that incorporated into positions 8 and 12 of terrecyclic acid A (Table 1). These results suggested the possible involvement of two different pools of isoprene precursors in the biosynthesis of terrecyclic acid A, a rare occurrence in terpene biosynthesis ${ }^{10)}$.

Incorporations obtained with ${ }^{13} \mathrm{C}$-labeled acetate were much more uniform than that obtained with $\left[1-{ }^{13} \mathrm{C}\right]$ mevalonate. However, acetate experiments were regarded as inconclusive in assessing a twopool hypothesis due to the relatively large amount of isotopic dilution expected as two-carbon precursors are metabolically channeled into isoprene units. Incubations with $5-{ }^{13} \mathrm{C}$-labeled mevalonic acid gave high and uniform incorporations of label at positions 5, 7 and 9 (Fig. 2 and Table 1). These labeled positions are all methylene carbons, and signals and relative enrichments for these carbons were deemed more suitable for comparison than carbon atoms labeled with $\left[2-{ }^{13} \mathrm{C}\right]$ mevalonic acid. The results indicate the essential equivalency of each isoprene unit incorporated into terrecyclic acid A. 
Three isoprene units are involved in the biosynthesis of terrecyclic acid A. Initial cyclization of the farnesyl unit, and intramolecular hydride and carbon-carbon bond shifts suggested by HIROTA and CANE afford the terrecyclane carbon skeleton (Fig. 3) ${ }^{5,6)}$. In this scheme, atoms of the 15-carbon farnesyl precursor marked with the $(\times)$ and $(\bullet)$ ultimately become carbon atoms 5 and 4 of terrecyclic acid respectively. Interestingly, the $(\times)$-labeled carbon atom would derive from the second isoprene unit of farnesyl pyrophosphate while the (-labeled carbon atom would originate in the third isoprene unit of the 15 -carbon precursor. Allylic oxidation at position 4 and oxidation of the methyl group to a carboxylic acid functional group would afford terrecyclic acid. The recent identification of terrecyclol (3) as a metabolic product of the same strain of $A$. terreus would appear to support such a pathway ${ }^{11)}$.

\section{Acknowledgment}

We acknowledge with thanks, the financial support provided through NIH Grant CA 13786-10 by the National Cancer Institute.

\section{References}

1) Turner, W. B. \& D. C. Aldridge: Fungal Metabolites. II. pp. 22 549, Academic Press, New York, 1983

2) Calton, G. J.; R. L. Ranieri \& M. A. Espenshade: Quadrone, a new antitumor substance produced by Aspergillus terreus. Production, isolation and properties. J. Antibiotics 31: 38 42, 1978

3) Nakagawa, M.; A. Hirota, H. Sakai \& A. Isogai: Terrecyclic acid A, a new antibiotic from Aspergillus terreus. I. Taxonomy, production, and chemical and biological properties. J. Antibiotics 35: 778 782, 1982

4) Hirota, A.; M. Nakagawa, H. Sakai \& A. Isogai: Terrecyclic acid A, a new antibiotic from Aspergillus terreus. II. Structure of terrecyclic acid A. J. Antibiotics 35: 783 787, 1982

5) Hirota, A.; M. Nakagawa, H. Sakai \& A. Isogal: The biosynthesis of terrecyclic acid A, a novel sesquiterpene antibiotic. Agric. Biol. Chem. 48: 835 837, 1984

6) CANe, D. E.; Y. G. Whittle \& T.-C. Liang: The biosynthesis of quadrone and terrecyclic acid. Tetrahedron Lett. 25: 1119 1122, 1984

7) Betts, R. E.; D. E. Walters \& J. P. RosazZA: Microbial transformations of natural antitumor compounds. 1. Conversion of acronycine to 9-hydroxyacronycine by Cunninghamella echinulata. J. Med. Chem. 17: 599 602, 1974

8) Danishefsky, S.; K. Vaughan, R. Gadwood \& K. Tsuzuki: The total synthesis of $d$-quadrone. J. Am. Chem. Soc. 103: 4136 4141, 1981

9) Kingston, D. G. I.; M. X. Kolpak, J. W. LeFevre \& I. Borup-Grochtmann: Biosynthesis of antibiotics of the virginiamycin family. 3. Biosynthesis of virginiamycin $\mathrm{M}_{1}$. J. Am. Chem. Soc. 105: 5106 5110, 1983

10) Croteau, R.: Biosynthesis of monoterpenes. In Biosynthesis of Isoprenoid Compounds. Vol. 1. Eds., J. W. Porter \& S. L. Spurgeon, p. 235, Wiley Interscience, New York, 1981

11) Nakagawa, M.; H. Sakai, A. Isogai \& A. Hirota: Structure of a new antibiotic, terrecyclol, from Aspergillus terreus Thom. Agric. Biol. Chem. 48: 117 121, 1984 